Seminars, Conferences, Addresses

\title{
Islam and Ethnicity in Africa and the Middle East
}

State University of New York, Binghampton, NY Shawwäl 10-12, 14WUApril 25-27, 1991

This three-day seminar, sponsored by the State University of New York at Binghampton's Schweitzer Chair in Humanities, the South Asian and African Studies Program, the Department of African Studies, and the African American Institute, discussed the African experience, the Middle East experience, and crosscultural comparison.

The opening presentation was made by Ali Mazrui, who holds the Schweitzer Chair in Humanities at Binghampton. He discussed the interaction of Islam and ethnic cultures in Africa and pointed out that Islam and ethnicity are essentially contradictory concepts, one being a universalist and the other a particularist view of society. "But," according to him, "Islam has become ethnicized and ethnicity tends to become Islamized." The resulting tensions can be overcome only by a strong sense of human solidarity, such as the one which the Prophet talked about when he said that nobody excels in faith unless he loves for his brother what he loves for himself. 
Discussing the phenomenon of religious conversion, Humphrey Fisher (Univ. of London, UK) said that black African Muslims have lived by a "succession of paradigms" and that conversion is a continuing process within their communities.

Sulayman Nyang (Howard Univ., Washington, DC) described the cultural diversity and pluralism in Africa and said that Islam and other religions there are now called upon to live together within a framework of secular pluralism.

Carolyn Fluehr-Lobban (Rhode Island College, Providence, RI) questioned the concepts of Middle East and Black Africa and suggested the use of the term Afro-Arab or Afro-Asian.

Richard Antoun, (State Univ., Binghampton, NY) discussed the ethnic mosaic model and suggested that Muslims in the United States need to assert, affirm, and confirm their identity.

Oleg Graber (Princeton Univ., Princeton, NJ) observed that both religious groups and nation-states have at times fostered ethnic realities and at other times denied them, but none of them has adequately come to grips with them.

Donald Quataert (State Univ., Binghampton, NY) focused on economic factors in ethnicity and presented an analysis of the ethnic division of labor and state control of the workplace in the Middle East.

Ibrahim N. Shariff (Rutgers Univ., New Brunswick, NJ) made a presentation on ethnoaesthetics and focused on the impact of Islam on Swahili art. Islam had almost no effect on traditional African art, he said, but the intellectual and market functions of art as introduced into Africa by the West have undermined the foundations of the classical African arts and have led to their gradual destruction.

Papers on Islam and ethnoaesthetics, focusing on representations and other forms of art in Africa and the Middle East were also presented by Nkiru Nzegwu (State Univ., Binghampton, NY) and Irene Bierman (Univ. of California, Los Angeles, CA).

Moving into a different area, Ismail Serageldin (World Bank, Washington, DC) presented his paper on architecture and observed that there is certainly a search for architectural excellence in Muslim societies, but that there also seems to be a certain element of validation that they are looking for from the West, i.e., that only what is approved by the West is correct and good.

Frederick Denny (Univ. of Colorado, Boulder, CO) presented a comparative view of ethnic cultures among Muslims from such diverse Muslim countries as Egypt and Indonesia, and illustrated the point that ethnic influences are stronger than a common religion.

Fuad Khuri (Reading, UK), Michael Hillman (Univ. of Texas), and Sharif Mardin (Bogazici Univ., Turkey) made presentations on other aspects of Islam and ethnicity. 
Probably the most challenging proposition placed before the scholars attending the symposium was the one presented in an after-dinner speech by Akbar Muhammad (State Univ., Binghampton, NY). He analyzed the concept of ummah in the Qur'an and the hadith and asked the participants to consider whether that Islamic concept could really be used in thinking about the present-day concept of ethnicity.

Aftab A. Khan

State University College Buffalo, New York

\section{A New IIIT Publication}

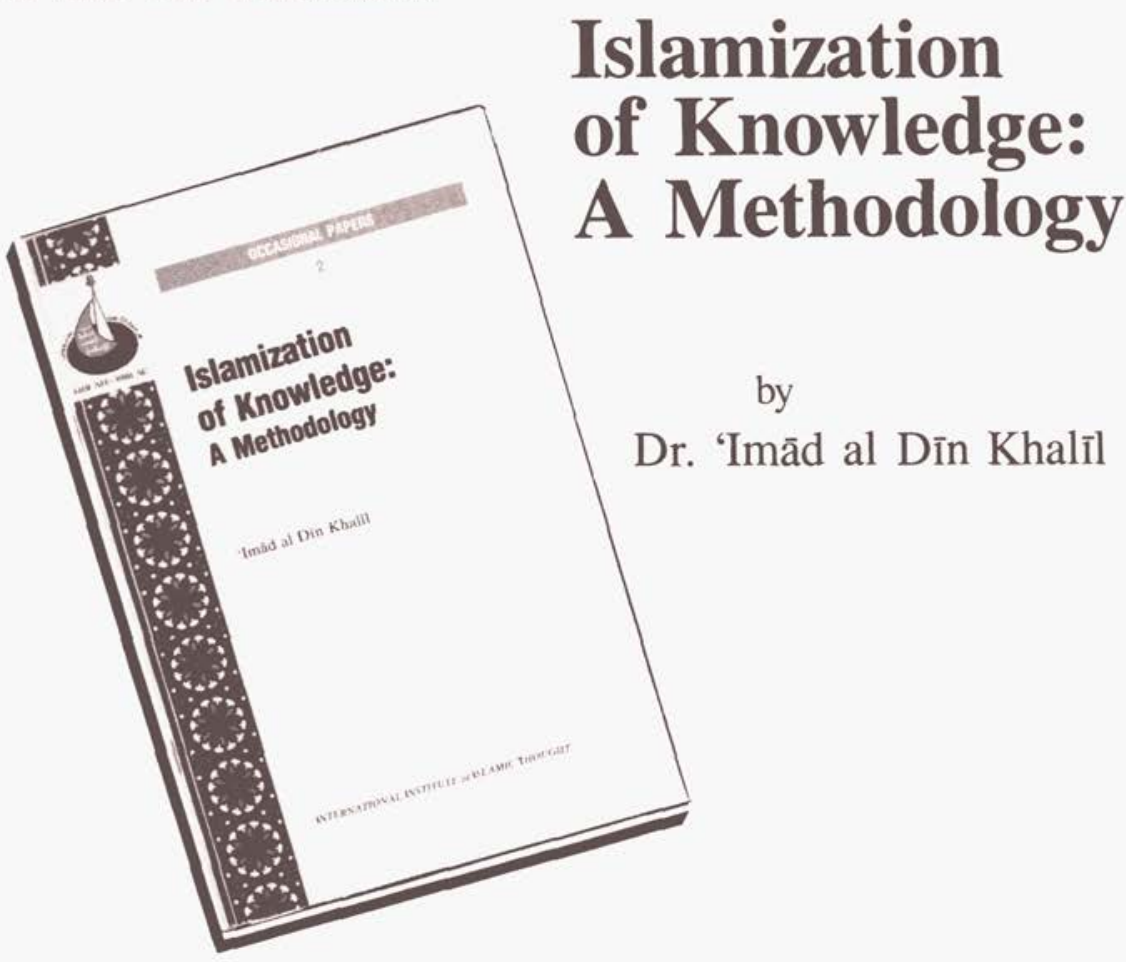

How the Islamization of Knowledge should be approached. The process has to pay due attention to the rich intellectual legacy of Islam and its role in modern thought. 